Ferrata Storti Foundation

\title{
A multicenter study of romiplostim for chemotherapy-induced thrombocytopenia in solid tumors and hematologic malignancies
}

Haematologica 2021

Volume 106(4):1148-1157

\section{Correspondence: \\ HANNY AL-SAMKARI \\ hal-samkari@mgh.harvard.edu \\ Received: March 5, 2020. \\ Accepted: May 27, 2020. \\ Pre-published: June 4, 2020.}

https://doi.org/10.3324/haematol.2020.251900

(C)2021 Ferrata Storti Foundation

Material published in Haematologica is covered by copyright. All rights are reserved to the Ferrata Storti Foundation. Use of published material is allowed under the following terms and conditions:

https://creativecommons.org/licenses/by-nc/4.0/legalcode. Copies of published material are allowed for personal or internal use. Sharing published material for non-commercial purposes is subject to the following conditions:

https://creativecommons. orǵ/licenses/by-nc/4.0/legalcode, sect. 3. Reproducing and sharing published material for commercial purposes is not allowed without permission in writing from the publisher.

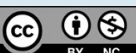

Hanny Al-Samkari, ${ }^{1,2}$ Aric D. Parnes, ${ }^{2,3,4}$ Katayoon Goodarzi, ${ }^{1,2}$ James I. Weitzman, ${ }^{2,5}$ Jean M. Connors ${ }^{2,3,4}$ and David J. Kuter ${ }^{1,2}$

${ }^{1}$ Division of Hematology Oncology, Massachusetts General Hospital, Boston, MA; ${ }^{2}$ Harvard Medical School, Boston, MA; ${ }^{3}$ Hematology Division, Brigham and Women's Hospital, Boston, MA; ${ }^{4}$ Department of Medical Oncology, Dana-Farber Cancer Institute, Boston, MA and ${ }^{5}$ Division of Hematology Oncology, Newton-Wellesley Hospital, Newton, MA, USA

\section{ABSTRACT}

hemotherapy-induced thrombocytopenia (CIT) frequently complicates cancer treatment causing chemotherapy treatment delays, dose reductions, and discontinuation. There is no US Food and Drug Administration (FDA)-approved agent available to manage CIT. This study retrospectively evaluated patients with CIT treated on institutional romiplostim treatment pathways at four US centers. The primary outcome was achievement of a romiplostim response (median on-romiplostim platelet count $\geq 75 \times 10^{9} / \mathrm{L}$ and $\geq 30 \times 10^{9} / \mathrm{L}$ above baseline). Secondary outcomes included time to platelet count $\geq 100 \times 10^{9} / \mathrm{L}$ and rates of the following: platelet count $<100 \times 10^{9} / \mathrm{L}$, platelet count $<75 \times 10^{9} / \mathrm{L}$, platelet count $<50 \times 10^{9} / \mathrm{L}$, thrombocytosis, chemotherapy dose reduction/treatment delay, platelet transfusion, bleeding, and thromboembolism. Multivariable regression was used to identify predictors of romiplostim non-response and compare weekly dosing with intracycle/intermittent dosing. A total of 173 patients (153 solid tumor, 20 lymphoma or myeloma) were treated, with 170 (98\%) receiving a median of four (range: 1-36) additional chemotherapy cycles on romiplostim. Romiplostim was effective in solid tumor patients: $71 \%$ of patients achieved a romiplostim response, $79 \%$ avoided chemotherapy dose reductions/treatment delays, and $89 \%$ avoided platelet transfusions. Median per-patient platelet count on romiplostim was significantly higher than baseline $\left(116 \times 10^{9} / \mathrm{L}\right.$ vs. $\left.60 \times 10^{9} / \mathrm{L} ; P<0.001\right)$. Bone marrow (BM) tumor invasion, prior pelvic irradiation, and prior temozolomide exposure predicted romiplostim non-response. Bleeding rates were lower than historical CIT cohorts and thrombosis rates were not elevated. Weekly dosing was superior to intracycle dosing with higher response rates and less chemotherapy dose reductions/treatment delays/bleeding; intracycle dosing had an incidence rate ratio (IRR) for dose reduction/treatment delay of 3.00 (95\%CI: 1.306.91; $P=0.010)$ and an IRR for bleeding of 4.84 (95\%CI: 1.18-19.89, $P=0.029)$ compared with weekly dosing. Blunted response (10\% response rate) was seen in non-myeloid hematologic malignancy patients with BM involvement. In conclusion, romiplostim was safe and effective for CIT in most solid tumor patients.

\section{Introduction}

Thrombocytopenia is frequent in cancer patients, usually due to myelosuppressive chemotherapy, tumor infiltration of the bone marrow (BM), or infection. ${ }^{1}$ Chemotherapy-induced thrombocytopenia (CIT) is a common complication of cytotoxic chemotherapy and many targeted therapies, occurring in approximately $15-25 \%$ of patients receiving platinum, taxane, and/or gemcitabine-based regimens. ${ }^{2}$ Currently there is no US Food and Drug Administration (FDA)-approved agent for CIT management. Platelet transfusion offers only temporary, unreliable 
improvement that is often impractical or impossible to continue for extended periods. Therefore, chemotherapy dose reductions and treatment delays are the current standard of care for the management of CIT, allowing platelet count to recover to the desired count for subsequent administration of cancer-directed treatment. Reduced relative dose intensity (RDI) that results from CIT-related treatment delays and dose reductions may reduce progression-free survival (PFS) and overall survival (OS)., ${ }^{3,4}$ Conversely, management or prevention of CIT with thrombopoietic agents may maintain RDI and improve OS, particularly in curable malignancies. ${ }^{5-8}$ Bleeding in CIT has major consequences for patient outcomes; patients with CIT who develop major bleeding have been shown to have substantially lower OS. ${ }^{4}$

Thrombopoietin receptor agonists (TPO-RA) have been developed and approved for use in immune thrombocytopenia (ITP), ${ }^{9}$ aplastic anemia, ${ }^{10}$ hepatitis C-associated thrombocytopenia, ${ }^{11}$ and perioperative thrombocytopenia. ${ }^{12-14}$ Romiplostim is a weekly subcutaneously-administered TPO-RA currently approved to treat ITP. Maximal doses of romiplostim are considerably more potent in raising the platelet count than the oral small molecule TPO-RA in healthy subjects and possibly in ITP, ${ }^{15-17}$ making this an ideal agent for investigation into myelosuppressive thrombocytopenias such as CIT. To date, studies of romiplostim to manage CIT have been limited to case series and small single-center studies. ${ }^{18-21}$ These studies suggest that romiplostim is effective in raising the platelet count in patients with solid tumors. Predictors of romiplostim non-response, optimal dosing regimens, and use in non-myeloid hematologic malignancies (lymphoma and myeloma) have not been evaluated. Clinical outcomes data more relevant than simple platelet count measurements, such as resumption of treatment without further chemotherapy dose reductions or treatment delays, bleeding, or thrombosis, are limited. The safety of TPO-RA in cancer patients is a concern, as TPORA carry an associated risk for venous thromboembolism (VTE), which could add to the baseline risk associated with malignancy.

The present study aims to address these questions and evaluate romiplostim to manage CIT in a large cohort of both solid tumor and hematologic malignancy patients treated at four affiliated US academic cancer centers. Institutional pathways guided administration of romiplostim at each center. Management of CIT remains an off-label use of romiplostim.

\section{Methods}

\section{Patients and data collection}

This study was approved by the Institutional Review Board of Partners Healthcare (approval PHS/2015000152). All patients aged $\geq 18$ years with thrombocytopenia treated with romiplostim to support administration of chemotherapy to treat solid tumors or non-myeloid hematologic malignancies (multiple myeloma, Hodgkin lymphoma or aggressive non-Hodgkin lymphoma) between July $1^{\text {st }} 2009$ and July $1^{\text {st }} 2019$ at the four participating institutions (Massachusetts General Hospital, Brigham and Women's Hospital, Dana-Farber Cancer Institute, and NewtonWellesley Hospital) were identified using the Research Patient Data Registry at Partners Healthcare. The specific patient data collected are available in the Online Supplementary Methods.

\section{Institutional romiplostim chemotherapy-induced thrombocytopenia pathways: weekly versus intracycle dosing}

Patients qualified to enter their institutional romiplostim CIT pathway after persistent thrombocytopenia (platelet count $<100 \times 10^{9} / \mathrm{L}$ ) at least 3 weeks from the date of last chemotherapy administration or after a delay in chemotherapy regimen initiation $\geq 1$ week due to thrombocytopenia. For solid tumor patients, two institutions utilized a weekly romiplostim CIT pathway in which romiplostim was administered weekly irrespective of timing of chemotherapy administration and two utilized an intracycle romiplostim CIT pathway in which romiplostim was administered primarily on chemotherapy offweeks, on average twice per month (see Figure 1 for dosing pathways). Regardless of pathway, platelet counts were obtained weekly. All hematologic malignancy patients were treated at institutions that employed the weekly romiplostim treatment pathway.

\section{Effectiveness and safety measures}

The primary outcome was achievement of a romiplostim response, defined as a median on-romiplostim platelet count $\geq 75 \times 10^{9} / \mathrm{L}$ and at least $30 \times 10^{9} / \mathrm{L}$ higher than the pretreatment baseline. Median on-romiplostim platelet counts were used in all analyses comparing individual patient baseline platelet count to individual patient on-romiplostim platelet count. As romiplostim response is a measure of effectiveness over the entire duration of romiplostim treatment, the time from romiplostim initiation to first achievement of platelet count $\geq 100 \times 10^{9} / \mathrm{L}$ was also evaluated. Because there is no universally accepted platelet count threshold that defines CIT recurrence, incidence rates of all measured platelet counts below thresholds of $50 \times 10^{9} / \mathrm{L}, 75 \times 10^{9} / \mathrm{L}$, and $100 \times 10^{9} / \mathrm{L}$ were also evaluated. Similarly, thrombocytosis was defined as $>400 \times 10^{9} / \mathrm{L}$ and incidence rates were evaluated.

Other clinical outcomes included rates of chemotherapy intensity reduction (dose reduction or treatment delay) specifically for thrombocytopenia and rates of platelet transfusion, bleeding, and arterial or venous thromboembolic events.

Patients treated with romiplostim for CIT but not able to resume chemotherapy were included in analyses of bleeding, VTE, and platelet count outcomes while on romiplostim treatment but not analyses of chemotherapy intensity reduction or platelet transfusion.

\section{Predictors of romiplostim non-response}

Predictors of failure to achieve a romiplostim response (referred to hereafter as "predictors of romiplostim nonresponse") were evaluated using a multivariable logistic model (see Online Supplementary Methods for development of the model).

\section{Statistical analysis}

Median individual patient platelet counts on romiplostim support were compared with the pre-romiplostim baseline platelet count with the Wilcoxon signed-rank test. Predictors of romiplostim non-response were identified using a multivariable logistic model (see Online Supplementary Methods).

Solid tumor patients receiving weekly versus intracycle dosing were compared. Rates of thrombosis, bleeding, chemotherapy delay/dose reduction, platelet transfusion, and platelet counts $<50 \times 10^{9} / \mathrm{L},<75 \times 10^{9} / \mathrm{L},<100 \times 10^{9} / \mathrm{L}$, and $>400 \times 10^{9} / \mathrm{L}$ were compared in the two groups with negative binomial regression models (see Online Supplementary Methods). Baseline and median onromiplostim platelet counts for each group were compared with the Mann-Whitney U test. 


\section{Results}

\section{Patients' characteristics}

A total of 173 patients (153 solid tumor, 20 hematologic malignancy) were treated for CIT with romiplostim to facilitate ongoing chemotherapy administration. Table 1 lists patients' baseline characteristics. Colorectal, hepatobiliary, pancreatic, and gastroesophageal cancers were the most common malignancies in the cohort, accounting for half of all patients treated. A total of 170 patients (98\%; 150 solid tumor and 20 hematologic malignancy) were able to receive additional chemotherapy, receiving a median of four (range: 1-36) additional chemotherapy cycles over a median of 10 (range: 2-125) weeks of romiplostim support. This totaled 60.7 patient-years $(3,163$ patientweeks) of romiplostim treatment of CIT and 1,063 supported cycles of chemotherapy in the entire cohort. Of the hematologic malignancy patients, 13 had aggressive lymphoma and seven had multiple myeloma; all had known BM involvement by tumor.

Platinum, gemcitabine, temozolomide, and taxanebased regimens most commonly precipitated CIT and were most frequently supported with romiplostim. Online Supplementary Table S1 details chemotherapy regimens precipitating CIT and supported on romiplostim.

\section{Romiplostim dosing}

For the entire cohort as well as solid tumor patients only, the median starting dose of romiplostim was $3 \mu \mathrm{g} / \mathrm{kg}$ (interquartile range [IOR], 2-3 $\mu \mathrm{g} / \mathrm{kg}$ ) and the median optimized dose of romiplostim (the dose at which platelet count $\geq 100 \times 10^{9} / \mathrm{L}$ was achieved in patients achieving this threshold) was $3 \mu \mathrm{g} / \mathrm{kg}$ (IOR: $2-5 \mu \mathrm{g} / \mathrm{kg}$ ).

The median starting dose for hematologic malignancy patients was $2 \mu \mathrm{g} / \mathrm{kg}$ (IOR: $2-4 \mu \mathrm{g} / \mathrm{kg}$ ) and median optimized dose was $3 \mu \mathrm{g} / \mathrm{kg}$ (IOR: $2-5 \mu \mathrm{g} / \mathrm{kg}$ ). Only seven $(30 \%)$ hematologic malignancy patients achieved platelet count $\geq 100 \times 10^{9} / \mathrm{L}$ and were therefore included in this median. Of the 13 hematologic malignancy patients not achieving platelet count $\geq 100 \times 10^{9} / \mathrm{L}$, only one was titrated to maximum dose romiplostim (10 $\mu \mathrm{g} / \mathrm{kg})$.

\section{Effect of romiplostim on platelet counts and rates of romiplostim response in solid tumor patients}

Median individual patient platelet counts on romiplostim were significantly higher than at baseline in the entire cohort $\left(112 \times 10^{9} / \mathrm{L}\right.$ vs. $\left.54 \times 10^{9} / \mathrm{L} ; P<0.001\right)$ and in solid tumor patients alone $\left(116 \times 10^{9} / \mathrm{L}\right.$ vs. $\left.60 \times 109 / \mathrm{L} ; P<0.001\right)$. Figure 2A illustrates median weekly platelet counts on romiplostim support for solid tumor patients.

The rate of romiplostim response (achieving a median on-romiplostim platelet count $\geq 75 \times 10^{9} / \mathrm{L}$ and at least $30 \times 10^{9} / \mathrm{L}$ higher than the pretreatment baseline) was $71 \%$ for all solid tumor patients and $82 \%$ for those patients without predictors of romiplostim non-response (see "Predictors of romiplostim non-response in solid tumor patients" below).

Of all 153 solid tumor patients, $130(85 \%)$ achieved platelet count $\geq 100 \times 10^{9} / \mathrm{L}$ on romiplostim therapy, with a median time from romiplostim initiation to achievement of these values of 9 days (interquartile range [IOR] 7-15 days). After excluding patients with predictors of romiplostim non-response (see below), 116 of 122 solid tumor patients $(95 \%)$ achieved a platelet count $\geq 100 \times 10^{9} / \mathrm{L}$ on romiplostim therapy, with a median time to platelet count
Table 1. Baseline characteristics of patients $(n=173)$ treated with romiplostim for chemotherapy-induced thrombocytopenia (CIT) and American Joint Committee on Cancer (AJCC) staging.

\begin{tabular}{|c|c|}
\hline Characteristic & Value \\
\hline Age (years), mean (range) & $60(19-85)$ \\
\hline$\%$ female & 45 \\
\hline AJCC ${ }^{\mathrm{a}}$ stage & $\begin{array}{c}\text { I: } 2(1 \%) \\
\text { II: } 4(2 \%) \\
\text { III: } 17(10 \%) \\
\text { IV: } 128 \text { (74\%) } \\
\text { Not AJCC staged: } 22(13 \%)\end{array}$ \\
\hline $\begin{array}{l}\text { Duration of chemotherapy delay } \\
\text { due to CIT prior to romiplostim } \\
\text { (weeks), median (range) }\end{array}$ & $3(1-15)$ \\
\hline $\begin{array}{l}\text { Prior chemotherapy regimens, } \\
\text { median (range) }\end{array}$ & $2(1-11)$ \\
\hline $\begin{array}{l}\text { Cycles of current regimen prior } \\
\text { to romiplostim initiation, } \\
\text { median (range) }\end{array}$ & $2(1-55)$ \\
\hline Tumor type, N (\%) & $\begin{array}{c}\text { Breast } 11(6 \%) \\
\text { CNS } 15(9 \%)^{\mathrm{c}} \\
\text { Colorectal } 23(13 \%) \\
\text { Gastroesophageal } 18(10 \%) \\
\text { Genitourinary } 2(1 \%) \\
\text { Gynecologic } 11(6 \%) \\
\text { Head and neck } 5(3 \%) \\
\text { Hepatobiliary } 22(13 \%) \\
\text { Lung } 13(8 \%) \\
\text { Lymphoma } 13(8 \%) \\
\text { Myeloma } 7(4 \%) \\
\text { Neuroendocrine 6 (4\%) } \\
\text { Pancreatic } 22(13 \%) \\
\text { Sarcoma } 5(3 \%)\end{array}$ \\
\hline
\end{tabular}

${ }^{a}$ AJCC staging for solid tumors, Lugano modification of Ann Arbor staging for lymphomas. ${ }^{\text {b Includes } 15}$ patients with primary central nervous system (CNS) tumors and seven patients with myeloma. 'Patients with primary CNS lymphoma are classified as part of this group.

$\geq 100 \times 10^{9} / \mathrm{L}$ of 9 days (IOR 7-14 days). Statistics of additional time to platelet count $\geq 100 \times 10^{9} / \mathrm{L}$ are listed in Online Supplementary Table S2.

\section{Predictors of romiplostim non-response in solid tumor patients}

Eight different chemotherapeutics administered to patients prior to development of CIT met criteria for inclusion in the multivariable logistic model evaluating predictors of romiplostim non-response: cisplatin, carboplatin, oxaliplatin, gemcitabine, fluorouracil, irinotecan, temozolomide, and the taxane class (paclitaxel, docetaxel, or cabazitaxel). In a multivariable logistic model with romiplostim response as the dependent variable, and age, sex, biopsy-proven tumor BM invasion, prior pelvic irradiation, and these chemotherapeutics as independent variables, three variables predicted a significantly lower likelihood of romiplostim response: BM invasion (odds ratio [OR] 0.029, 95\% confidence interval [CI]: 0.0046-0.18; $P<0.001$ ), prior pelvic irradiation (OR $0.078,95 \% \mathrm{CI}$ : $0.0062-0.98 ; P=0.048$ ), and prior exposure to temozolomide (OR 0.24, 95\%CI: 0.061-0.96; $P=0.043$ ). On-romiplostim platelet counts were considerably lower in patients with these characteristics (Figure 2B) and were reflected in rates of romiplostim response of $23 \%, 20 \%$, and $46 \%$, respectively. Taken together, 14 of 31 of these 
Table 2. Venous thromboembolic events in cohort while on romiplostim treatment for chemotherapy-induced thrombocytopenia (CIT) and within 30 days of romiplostim discontinuation.

\begin{tabular}{|c|c|c|c|}
\hline Patient information & Type of VIE & Platelet count at VIE & Notes \\
\hline 46 y M, Astrocytoma & Proximal lower extremity DVT & $150 \times 10^{9} / \mathrm{L}$ & \\
\hline 61 y M, Pancreatic Ca Stage IIB & $\begin{array}{c}\text { Peripherally inserted } \\
\text { central venous catheter-associated } \\
\text { upper extremity DVT }\end{array}$ & $119 \times 10^{9} / \mathrm{L}$ & \\
\hline 49 y F, Cervical Ca Stage IV & Renal vein thrombosis & $147 \times 10^{9} / \mathrm{L}$ & \\
\hline 58 y M, Pancreatic Ca Stage III & Segmental PE, splenic infarct & $146 \times 10^{9} / \mathrm{L}$ & \\
\hline 67 y M, Pancreatic Ca Stage IV & Proximal lower extremity DVT & $156 \times 10^{9} / \mathrm{L}$ & \\
\hline 67 y M, Cholangiocarcinoma Stage IV & $\begin{array}{c}\text { Central venous } \\
\text { catheter-associated } \\
\text { internal jugular vein thrombus }\end{array}$ & $65 \times 10^{9} / \mathrm{L}$ & \\
\hline 53 y M, Cholangiocarcinoma Stage IV & $\begin{array}{c}\text { Bilateral distal } \\
\text { lower extremity DVT }\end{array}$ & $307 \times 10^{9} / \mathrm{L}$ & $\begin{array}{l}\text { Occurred in setting of hospitalization, } \\
\text { following T4 compression fracture, } \\
\text { bilateral thoracic decompression surgery; } \\
\text { thrombocytosis with platelet count in } \\
500-600 \times 10^{9} / \mathrm{L} \text { range present the week prior }\end{array}$ \\
\hline 59 y M, Pancreatic Ca Stage IV & Segmental PE & $118 \times 10^{9} / \mathrm{L}$ & \\
\hline
\end{tabular}

Plt: platelet count; Ca: cancer;VTE: venous thromboembolism; y: years; M: male; F: female; DVT: deep venous thrombosis; PE: pulmonary embolus.

Table 3. Bleeding events in cohort while on romiplostim treatment for chemotherapy-induced thrombocytopenia (CIT).

\begin{tabular}{|c|c|c|c|c|c|c|c|}
\hline Patient information & $\begin{array}{l}\text { Type of } \\
\text { bleed }\end{array}$ & $\begin{array}{l}\text { Platelet } \\
\text { count } \\
\text { at bleed }\end{array}$ & $\begin{array}{c}\text { On } \\
\text { anticoagulation } \\
\text { at bleed? }\end{array}$ & $\begin{array}{l}\text { WhO } \\
\text { grade }\end{array}$ & $\begin{array}{l}\text { CTCAE } \\
\text { v. } 4.03 \\
\text { grade }\end{array}$ & $\begin{array}{c}\text { Red cell } \\
\text { transfusion } \\
\text { requirements }\end{array}$ & Notes \\
\hline 84 y M, DLBCL Stage IV & $\begin{array}{c}\text { Subdural } \\
\text { hematoma }\end{array}$ & $198 \times 10^{9} / \mathrm{L}$ & No & 4 & 2 & None & $\begin{array}{c}\text { Occurred } \\
\text { after a fall and } \\
\text { strike to } \\
\text { the head }\end{array}$ \\
\hline $\begin{array}{l}61 \text { y M, Pancreatic } \\
\text { Ca Stage IIB }\end{array}$ & $\begin{array}{l}\text { Upper } \\
\text { GI bleed }\end{array}$ & $142 \times 10^{9} / \mathrm{L}$ & No & 4 & 4 & $\begin{array}{l}9 \text { units } \\
\text { pRBC }\end{array}$ & $\begin{array}{l}\text { Bleeding from } \\
\text { duodenal ulcer }\end{array}$ \\
\hline 63 y F, SCLC Stage IV & $\begin{array}{c}\text { Hemorrhagic } \\
\text { brain metastases }\end{array}$ & $55 \times 10^{9} / \mathrm{L}$ & No & 4 & 1 & None & $\begin{array}{l}\text { Asymptomatic, } \\
\text { incidentally } \\
\text { discovered }\end{array}$ \\
\hline 59 y M, GIST Stage IV & Upper GI bleed & $115 \times 10^{9} \mathrm{~L}$ & $\begin{array}{c}\text { Yes } \\
\text { (fondaparinux) }\end{array}$ & 4 & 4 & 6 units $\mathrm{pRBC}$ & \\
\hline $\begin{array}{l}85 \text { y M, Pancreatic Ca } \\
\text { Stage IIB }\end{array}$ & $\begin{array}{l}\text { Oral mucosa } \\
\text { bleeding }\end{array}$ & $19 \times 10^{9} / \mathrm{L}$ & Yes (rivaroxaban) & 1 & 1 & None & \\
\hline 74 y M, NSCLC Stage IV & $\begin{array}{l}\text { Upper GI } \\
\text { bleed }\end{array}$ & $80 \times 10^{9} / \mathrm{L}$ & Yes (aspirin) & 3 & 3 & 3 units $\mathrm{pRBC}$ & \\
\hline $\begin{array}{l}40 \text { y F, Endometrial Ca } \\
\text { Stage IV }\end{array}$ & $\begin{array}{l}\text { Lower } \\
\text { GI bleed }\end{array}$ & $49 \times 10^{9} / \mathrm{L}$ & No & 3 & 3 & 4 units $\mathrm{pRBC}$ & $\begin{array}{l}\text { In setting of } \\
\text { radiation } \\
\text { proctitis }\end{array}$ \\
\hline $\begin{array}{l}40 \text { y F, Endometrial Ca } \\
\text { Stage IV }\end{array}$ & $\begin{array}{l}\text { Lower GI } \\
\text { bleed }\end{array}$ & $49 \times 10^{9} / \mathrm{L}$ & No & 3 & 3 & 9 units $\mathrm{pRBC}$ & $\begin{array}{l}\text { In setting } \\
\text { of radiation } \\
\text { proctitis }\end{array}$ \\
\hline
\end{tabular}

60 y F, Lung $\mathrm{Ca}$

72 y F, Endometrial Ca

Stage IV

58 y M, Pancreatic Ca Stage III Upper

GI bleed

66 y M, Cholangiocarcinoma Epistaxis

Stage IV
Stage IV

Cutaneous

ecchymoses

$11 \times 10^{9} / \mathrm{L}$

No

$10 \times 10^{9} / \mathrm{L}$

No

$170 \times 10^{9} / \mathrm{L}$

$82 \times 10^{9} / \mathrm{L}$

No

No

$79 \times 10^{9} / \mathrm{L} \quad$ Yes (rivaroxaban)

$239 \times 10^{9} / \mathrm{L}$

No

3

3 units pRBC

Ca: cancer; CTCAE: Common Terminology Criteria for Adverse Events; DLBCL: diffuse large B-cell lymphoma; GI: gastrointestinal; NSCLC: non-small cell lung cancer; Plt: platelet

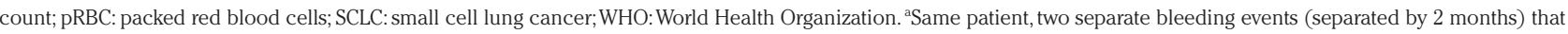
each occurred at the same platelet count. 


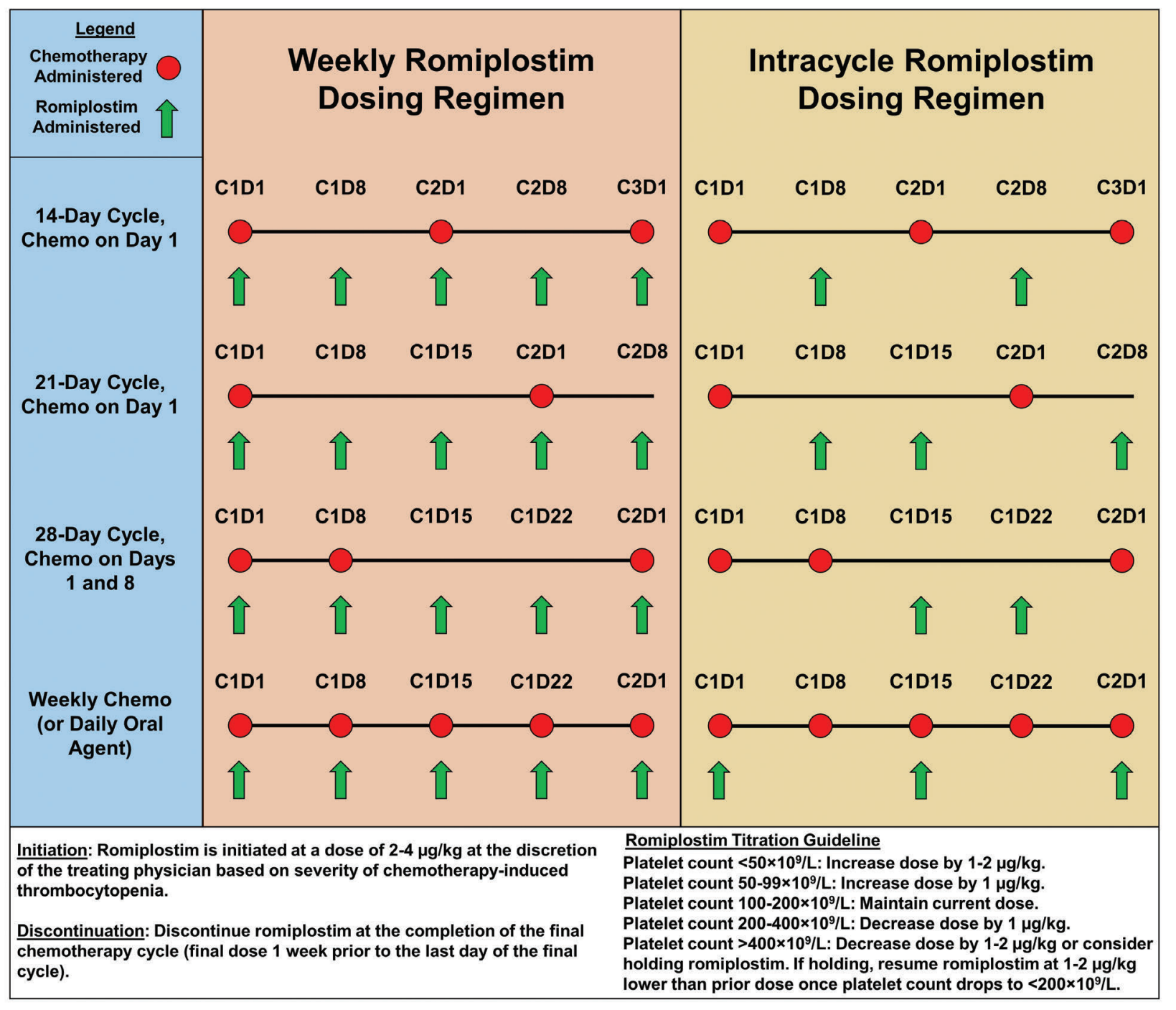

Figure 1. Chemotherapy-induced thrombocytopenia (CIT) romiplostim treatment pathways. In the weekly romiplostim dosing pathway, romiplostim is administered weekly irrespective of treatment schedule. In the intracycle romiplostim dosing pathway, romiplostim is dosed on chemotherapy off-weeks, except for chemotherapy regimens employing regular treatment without off-weeks in which case romiplostim is administered every other week. Platelet counts are obtained weekly in both pathways.

patients $(45 \%)$ achieved platelet count $\geq 100 \times 10^{9} / \mathrm{L}$ on romiplostim therapy, with a median time to platelet count $\geq 100 \times 10^{9} / \mathrm{L}$ of 17 days (IOR 8-24 days). This poor rate of response was observed despite substantial romiplostim dose-escalation in these patients (median romiplostim dose, $8 \mu \mathrm{g} / \mathrm{kg}$ [IOR, 5-10 $\mu \mathrm{g} / \mathrm{kg}]$ ).

\section{Clinical effectiveness and safety outcomes in solid} tumor patients

In the 150 solid tumor patients able to continue chemotherapy with romiplostim treatment, number of events and event rates over the 57.7 patient-years at risk were as follows: chemotherapy intensity reduction, 89 events resulting in a rate of 154 events per 100 patientyears at risk; bleeding, 13 events resulting in a rate of 23 events per 100 patient-years at risk; VTE, eight events resulting in a rate of 14 events per 100 patient-years at risk; and platelet transfusion, 62 events resulting in a rate of 107 events per 100 patient-years at risk. Excluding patients with predictors of romiplostim non-response
(50.0 patient-years at risk), number and rates of these outcomes declined as follows: chemotherapy intensity reduction, 65 events, rate 130 per 100 patient-years at risk; bleeding, eight events, rate 16 per 100 patient-years at risk; VTE, seven events, rate 14 per 100 patient-years at risk; and platelet transfusion, 13 events, rate 26 events per 100 patient-years at risk. Of all solid tumor patients 118 out of $150(79 \%)$ had no chemotherapy intensity reductions and 133 out of $150(89 \%)$ required no platelet transfusions while on romiplostim. There were no arterial thromboembolic events. Tables 2 and 3, respectively, describe the individual VTE and bleeding events in the patient cohort. No patient died of bleeding or thrombosis. The three patients given romiplostim but not able to resume chemotherapy did not experience bleeding or thrombotic events on romiplostim.

Comparison of weekly romiplostim dosing versus intracycle romiplostim dosing in solid tumor patients

Of the solid tumor patients, 80 were treated on the 
A

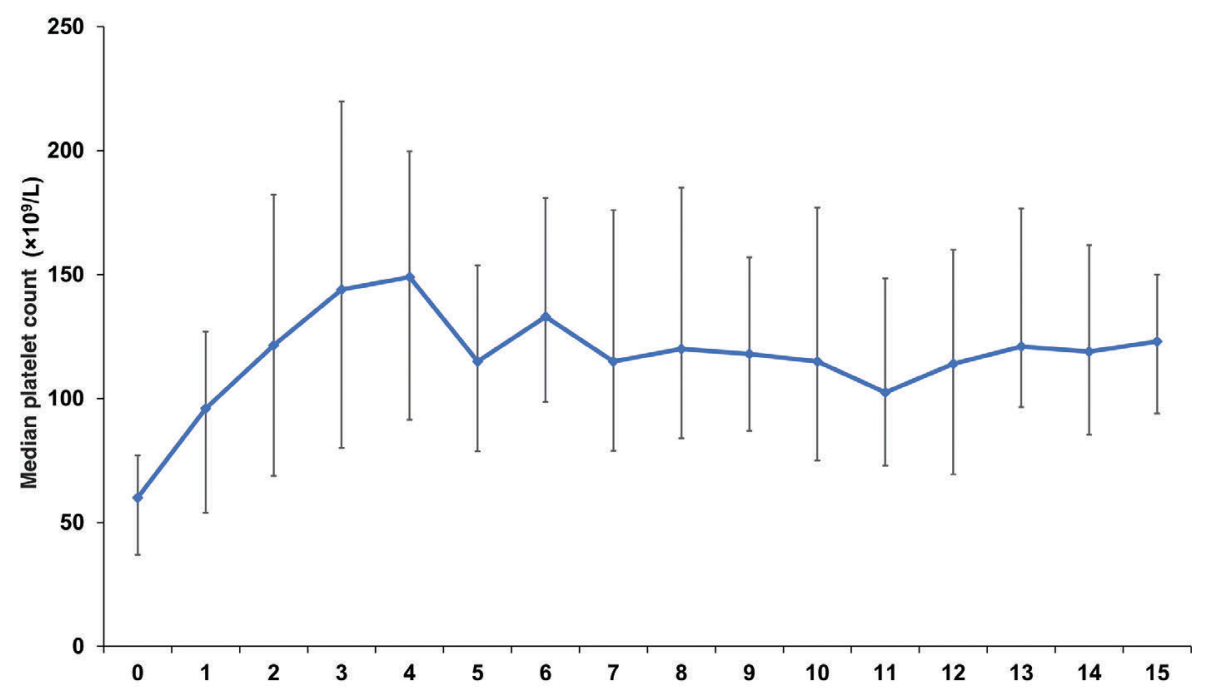

Figure 2. Median weekly platele counts for patients on romiplostim chemotherapy-induced thrombocytopenia (CIT) treatment pathway. (A) Solid tumor patients $(n=153)$. Error bars represent interquartile ranges. (B) Solid tumor patients with no predictors of romiplostim nonresponse $(n=122$, blue); solid tumor patients with predictors of romiplostim non-response $(n=31$, gray) including bone marrow (BM) invasion by tumor, prior pelvic irradiation, or prior temozolomide treatment; aggressive lymphoma patients $(n=13$, red); and myeloma patients ( $n=7$, purple). Error bars omitted for figure clarity. PNR: predictors of romiplostim non-response (includes BM invasion by tumor, prior temozolomide exposure, or prior pelvic irradiation)

B

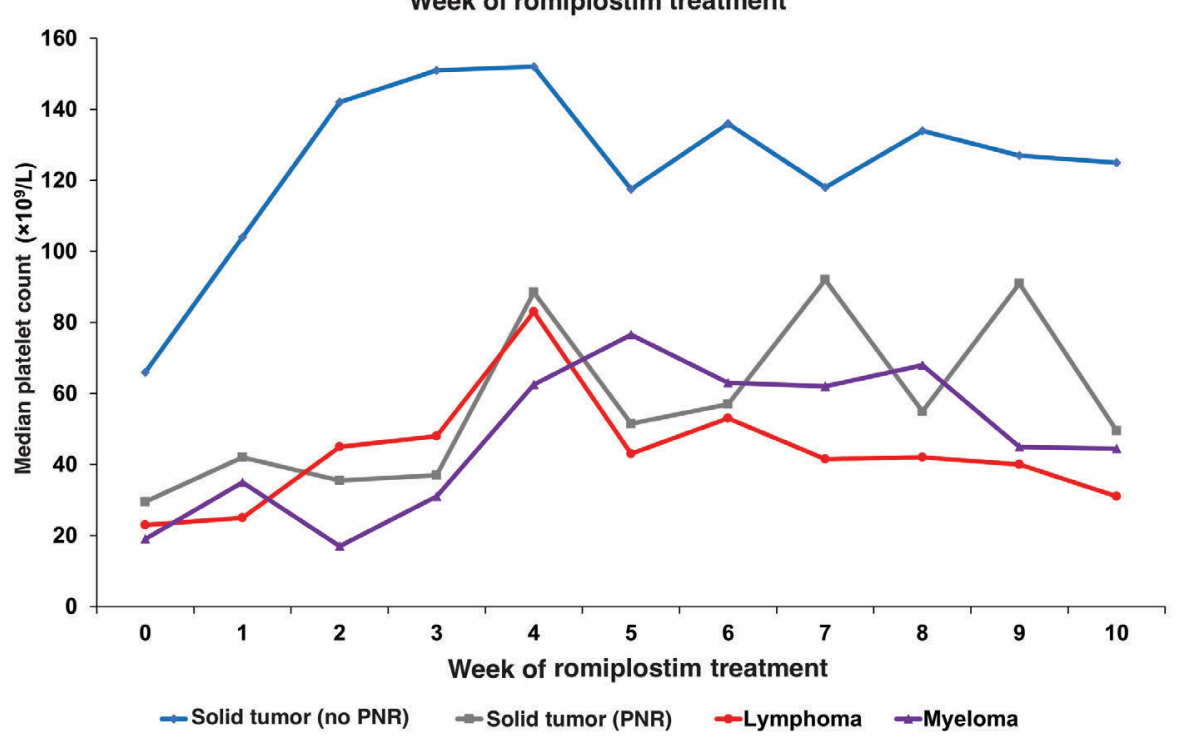

weekly romiplostim dosing pathway and 73 were treated on the intracycle romiplostim dosing pathway (Figure 1). Table 4 describes differences in clinical and platelet count outcome between the two groups. Patients receiving weekly dosing had a significantly higher median platelet count on romiplostim $\left(143 \times 10^{9} / \mathrm{L}\right.$ vs. $\left.106 \times 10^{9} / \mathrm{L} ; P<0.001\right)$ and a higher rate of achieving a romiplostim response ( $81 \%$ vs. $63 \% ; P=0.006$ ). Figure 3 illustrates the difference in median weekly platelet counts for each cohort. Using negative binomial regression modeling controlling for demographics and predictors of romiplostim nonresponse, intracycle dosing had higher rates of platelet counts measured $<50 \times 10^{9} / \mathrm{L},<75 \times 10^{9} / \mathrm{L}$, or $<100 \times 10^{9} / \mathrm{L}$ (see Table 4 for details), chemotherapy intensity reduction (incidence rate ratio [IRR] 3.00, 95\%CI: 1.30-6.91; $P=0.010$ ), and bleeding (IRR 4.84, 95\%CI: 1.18-19.89; $P=0.029)$ compared with weekly dosing, with similar rates of thromboembolism and platelet transfusion for chemotherapy administration.

\section{Outcomes in hematologic malignancy patients}

Median individual patient platelet counts on romiplostim were significantly higher than at baseline:
$46 \times 10^{9} / \mathrm{L}$ vs. $21 \times 10^{9} / \mathrm{L} ; P=0.003$. Figure $2 \mathrm{~B}$ illustrates median weekly platelet counts on romiplostim support for hematologic malignancy patients. The rate of romiplostim response in hematologic malignancy patients was $10 \%$. Seven of 20 hematologic malignancy patients $(35 \%)$ achieved a platelet count $\geq 100 \times 10^{9} / \mathrm{L}$ on romiplostim therapy, with a median time to platelet count $\geq 100 \times 10^{9} / \mathrm{L}$ of 24 days (IOR 19-36 days).

In the 20 hematologic malignancy patients treated (for 3.0 patient-years), there were nine chemotherapy intensity reduction events, one bleeding event (which was not fatal), 44 platelet transfusion events, and no thrombotic events.

Additional data on platelet count outcomes and the bleeding event in hematologic malignancy patients are given in Online Supplementary Tables S2 and S3, respectively.

\section{Discussion}

Initial studies of platelet growth factors to manage CIT utilized the first-generation thrombopoietic agents rhIL-11 
Table 4. Solid tumor patient dosing strategy comparison. Rates of platelet count measurements describe the fraction of counts measured beyond a given platelet count threshold (mean rates for all patients in each group are given). Rates of clinical outcomes are exposure-adjusted (given as rates per 100 patient-years at risk).

\begin{tabular}{|c|c|c|c|c|c|c|}
\hline \multirow{2}{*}{ Outcome } & \multicolumn{2}{|c|}{ Weekly regimen } & \multicolumn{2}{|c|}{ Intracycle regimen } & \multirow{2}{*}{$\begin{array}{l}\text { Intracycle } \\
\text { vs. weekly }\end{array}$} & \multirow[t]{2}{*}{$\boldsymbol{P}$} \\
\hline & All $\left(\mathbb{N}=80^{2}\right)$ & No PNR $\left(N=65^{b}\right)$ & All $\left(N=73^{9}\right)$ & No PNR (N=57) & & \\
\hline Weekly platelet count measurements ${ }^{\#}$ & 1,154 & 1,049 & 1,287 & 1,142 & & \\
\hline Baseline median platelet count & $54 \times 10^{9} / \mathrm{L}$ & $61 \times 10^{9} / \mathrm{L}$ & $66 \times 10^{9} / \mathrm{L}$ & $70 \times 10^{9} / \mathrm{L}$ & & $\begin{array}{c}\text { All: } 0.27^{*} \\
\text { No PNR: } 0.35^{*}\end{array}$ \\
\hline On-romiplostim median platelet count & $143 \times 10^{9} / \mathrm{L}$ & $146 \times 10^{9} / \mathrm{L}$ & $106 \times 10^{9} / \mathrm{L}$ & $110 \times 10^{9} / \mathrm{L}$ & & $\begin{array}{c}\text { All: }<0.001^{*} \\
\text { No PNR: }<0.001^{*}\end{array}$ \\
\hline Achieved romiplostim response (\%) & $63(81 \%)$ & $61(95 \%)$ & $45(63 \%)$ & $39(68 \%)$ & $0.28(0.11-0.69)^{\dagger}$ & 0.006 \\
\hline \multicolumn{7}{|c|}{ Mean rate of platelet count measurements beyond thresholds on romiplostim } \\
\hline Platelet count measured $<50 \times 10^{9} / \mathrm{L}$ & 0.13 & 0.032 & 0.18 & 0.090 & $1.72(1.01-2.90)^{\dagger}$ & 0.043 \\
\hline Platelet count measured $<75 \times 10^{9} / \mathrm{L}$ & 0.21 & 0.10 & 0.32 & 0.24 & $1.72(1.26-2.35)^{\dagger}$ & 0.001 \\
\hline Platelet count measured $<100 \times 10^{9} / \mathrm{L}$ & 0.31 & 0.21 & 0.49 & 0.44 & $1.74(1.38-2.20)^{\dagger}$ & $<0.001$ \\
\hline Platelet count measured $>400 \times 10^{9} / \mathrm{L}$ & 0.050 & 0.060 & 0.029 & 0.026 & $0.39(0.11-1.40)^{\dagger}$ & 0.14 \\
\hline \multicolumn{7}{|c|}{ Rates of clinical outcomes per 100 patient-years at risk (100 patient-years on romiplostim support) } \\
\hline $\begin{array}{l}\text { Chemotherapy intensity reduction } \\
\text { (dose reduction or treatment delay) }\end{array}$ & 82 & 76 & 224 & 178 & $3.00(1.30-6.91)^{\S}$ & 0.010 \\
\hline Platelet transfusion & 96 & 38 & 118 & 15 & $0.89(0.19-4.23)^{\S}$ & 0.89 \\
\hline Bleeding event & 11 & 13 & 34 & 19 & $4.84(1.18-19.89)^{\S}$ & 0.029 \\
\hline Venous thromboembolic event & 7.1 & 8.4 & 20 & 19 & $2.60(0.51-13.25)^{\S}$ & 0.25 \\
\hline
\end{tabular}

PNR: predictors of romiplostim non-response (includes bone marrow [BM] invasion by tumor, prior temozolomide exposure, or prior pelvic irradiation). 80 patients received weekly dosing, of which two could not resume chemotherapy. All 80 are included in the platelet count outcome analyses but only the 78 able to restart chemotherapy are includ ed in the clinical outcome analyses. ${ }^{\text {b}}$ Sixty-five patients without predictors of romiplostim non-response received weekly dosing, of which one could not resume chemotherapy. All 65 are included in the platelet count outcome analyses but only the 64 able to restart chemotherapy are included in the clinical outcome analyses. ${ }^{~}$ Seventy-three patients without predictors of romiplostim non-response received intracycle dosing, of which one could not resume chemotherapy. All 73 are included in the platelet count outcome analyses but only the 72 able to restart chemotherapy are included in the clinical outcome analyses. * By Mann-Whitney U Test. ${ }^{\dagger}$ The value is the odds ratio with a $95 \%$ confidence interval, calculated from a multivariable logistic regression model with romiplostim response as the dependent variable and age, dosing regimen, BM invasion, prior pelvic irradiation, and prior temozolomide exposure as independent variables. ${ }^{*}$ The value is the rate ratio with a $95 \%$ confidence interval, calculated from multivariable negative binomial regression models with the given platelet count threshold as the dependent variable, number of platelet count measurements as the exposure variable, and age, dosing regimen BM invasion by tumor, prior pelvic irradiation, and prior temozolomide exposure as independent variables. ${ }^{\text {\$ }}$ The value is the rate ratio with a $95 \%$ confidence interval, calculated from multivariable negative binomial regression models with the given clinical outcome as the dependent variable, duration of romiplostim support as the exposure variable, and age, sex, dosing regimen, BM invasion by tumor, prior pelvic irradiation, and prior temozolomide exposure as independent variables.

(oprelvekin), rhTPO (recombinant human thrombopoietin), and PEG-rhMGDF (pegylated recombinant human megakaryocyte growth and development factor). These agents demonstrated efficacy in CIT management in clinical studies, reducing need for platelet transfusions, increasing overall and nadir platelet counts, and allowing for improved relative dose intensity. ${ }^{5,22-24}$ Unfortunately, development of recombinant thrombopoietins was halted in the West due to occurrence of antibodies to PEGrhMGDF with cross-reactivity to native TPO..$^{25}$ Oprelvekin was FDA-approved for CIT but use was limited due to an unfavorable side-effect profile; this agent is no longer available from the manufacturer. Notably, rhTPO, which is not associated with cross-reactive antibodies, completed development in China where it is a routine component of supportive care in cancer patients. ${ }^{26}$ More recent emergence of the TPO-RAs romiplostim, eltrombopag, and avatrombopag has renewed interest in pharmacologic CIT management in the West.

Four single-center studies, each evaluating between 2052 solid tumor patients receiving romiplostim for CIT, ${ }^{18-21}$ concluded that romiplostim is effective in raising the platelet count in CIT but did not compare different dosing strategies or characterize predictors of romiplostim nonresponse. None of these studies evaluated bleeding, the primary hazard of thrombocytopenia, and only limited data on the impact of romiplostim treatment on chemotherapy dose reductions and treatment delays were described. ${ }^{20,21}$ Treatment of CIT with romiplostim in nonmyeloid hematologic malignancy is currently limited to case reports. ${ }^{27}$ These factors provided the rationale behind the present study which aimed to address each of these important questions.

We found that romiplostim was effective for the management of CIT in solid tumor patients receiving a variety of different chemotherapy regimens, with $98 \%$ (150 of 153) able to continue receiving chemotherapy with romiplostim support. Romiplostim treatment more than doubled the median platelet count of the cohort (from $54 \times 10^{9} / \mathrm{L}$ to $112 \times 10^{9} / \mathrm{L}$ ) enabling $79 \%$ of solid tumor patients to proceed without further chemotherapy dose reductions or treatment delays due to thrombocytopenia and $89 \%$ to proceed without platelet transfusions. The use of romiplostim for CIT in patients with solid tumors may improve outcomes of cancer treatment by allowing maintenance of dose intensity. Weekly romiplostim dosing, as compared with intracycle romiplostim dosing, resulted in fewer recurrences of CIT, chemotherapy dose reductions/treatment delays, and bleeding events (Table 4). Thrombocytosis rates were higher but VTE rates were similar. The lower overall exposure to romiplostim in patients treated with intracycle dosing as compared with weekly dosing may account for the differences in the observed outcomes between these two groups. Of note, intracycle dosing was still an effective strategy and could be considered as this reduces drug-associated costs. 


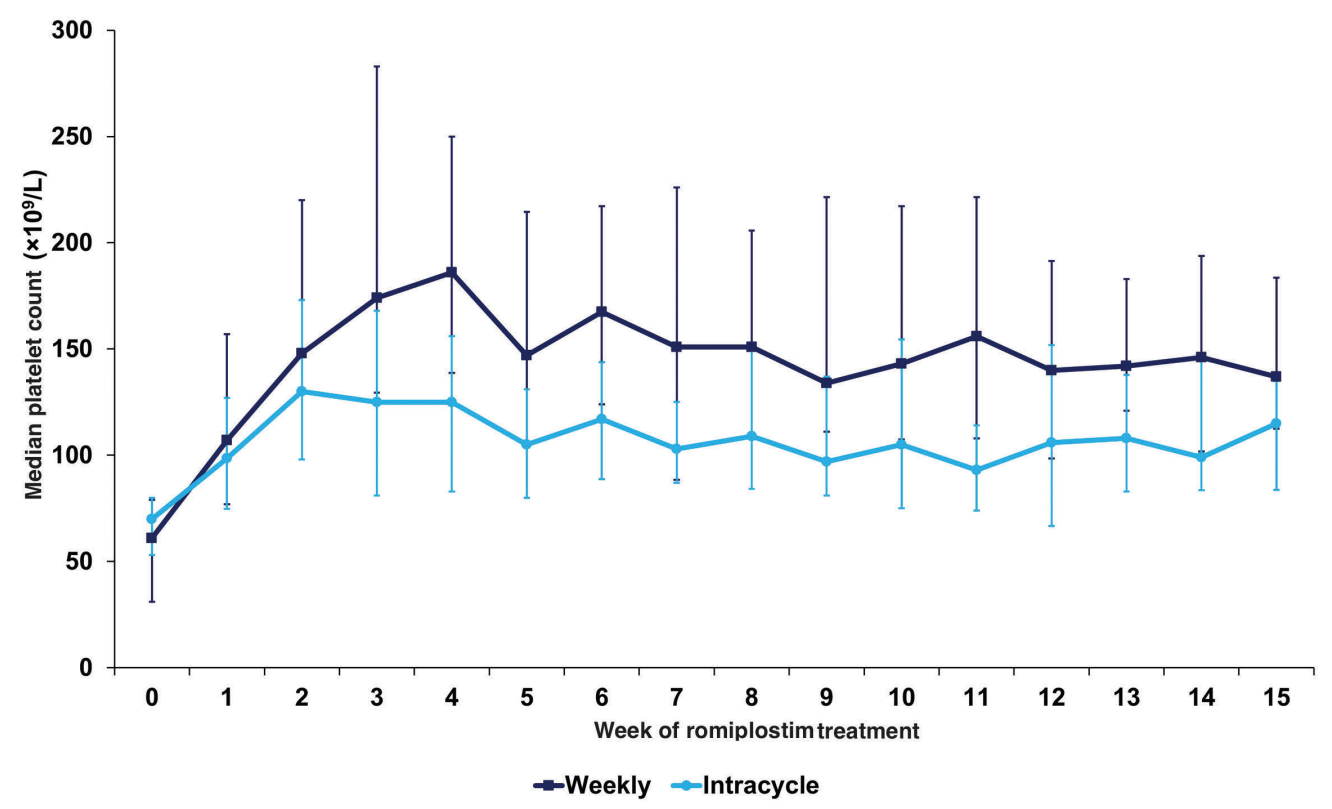

Figure 3. Median weekly platelet counts for solid tumor patients receiving standard weekly romiplostim dosing $(n=65$, dark blue) versus intracycle romiplostim dosing $(n=57$, light blue). Patients with predictors of romiplostim non-response (bone marrow invasion, prior pelvic irradiation, or prior temozolomide) were excluded from this figure to emphasize the difference specifically attributable to dosing regimen. Error bars represent interquartile ranges.

Given our large sample size, we were able to evaluate predictors of romiplostim non-response using multivariable logistic modeling; we found that BM invasion by tumor, prior pelvic irradiation, and prior exposure to temozolomide predict poor response to romiplostim treatment. The latter finding is consistent with the distinct risk of temozolomide resulting in severe marrow toxicity, ${ }^{28}$ made manifest by prolonged cytopenias or even aplastic anemia. Our findings suggest evaluation of CIT patients at high risk for $\mathrm{BM}$ involvement by tumor (such as patients with metastatic breast, prostate, or lung cancer with known bony involvement) with a BM biopsy may be appropriate before considering romiplostim treatment. Similarly, patients previously treated with pelvic irradiation or temozolomide may be better served with alternative approaches to CIT management. Studies of other thrombopoietic agents have demonstrated efficacy in treatment of CIT in lymphoma ${ }^{5}$ and demonstrated BM invasion by tumor as a predictor of romiplostim nonresponse in solid tumor patients. Given this, in this study, the overall subpar response of non-myeloid hematologic malignancy patients to romiplostim observed is likely secondary to known BM infiltration by malignancy, although many of these patients were not escalated to maximal doses of romiplostim. Additional studies of romiplostim to treat CIT in lymphoma patients without significant BM involvement are needed to better assess its utility in this population.

With 60.7 patient-years at risk of romiplostim treatment in this study, we were able to meaningfully evaluate rates of thromboembolic and bleeding events on romiplostim treatment. Eight patients developed a VTE event on romiplostim treatment, a rate of 14 VTE events per 100 patientyears. Given that $75 \%$ of our patients had metastatic disease (with one-third of those with localized disease having primary central nervous system malignancies which impart a high VTE risk) and approximately half had tumor types associated with higher VTE risk, this rate is consistent with VTE rates of 10-14 events per 100 patient-years described in epidemiologic studies of similar populations. ${ }^{29,30}$ No patient developing VTE had thrombocytosis at the time of VTE diagnosis, with platelet counts ranging between $65-307 \times 10^{9} / \mathrm{L}$ (Table 2). Solid tumor patients without predictors of romiplostim non-response had an overall bleeding rate of 16 events per 100 patient-years at risk, consistent with rates in the non-anti-coagulated, nonthrombocytopenic metastatic cancer population. ${ }^{31,32}$ This rate is considerably lower than rates in prior studies of CIT patients not treated with thrombopoietic agents. In a large retrospective study of 609 solid tumor and lymphoma patients with 1,262 chemotherapy cycles complicated by CIT, World Health Organization (WHO) grade 3 or 4 bleeding occurred in $43(3.4 \%)$ of cycles. ${ }^{4}$ The rate of WHO grade 3 or 4 bleeding in this study was just 11 out of 1,063 cycles supported with romiplostim (1.0\%), and many of these bleeds were likely unrelated to thrombocytopenia (only six occurred at platelet counts $<100 \times 10^{9} / \mathrm{L}$ and only three occurred at platelet counts $<50 \times 10^{9} / \mathrm{L}$ ) (Table 3). This same retrospective study also found dramatically higher rates of platelet transfusion and chemotherapy dose reduction and treatment delay than those observed in the present study. ${ }^{4}$

Our study has several limitations. As a retrospective, observational study, patients were treated with romiplostim according to institutional pathways that did not mandate strict adherence to treatment parameters. The overall study population was heterogeneous, including a number of different tumor types and chemotherapy regimens. As with many retrospective studies, there is the possibility of selection bias as the patient cohort was defined by those patients enrolled on the romiplostim treatment pathway without evaluating those that were not enrolled. The study was not randomized so cannot quantify the impact of romiplostim treatment compared with a placebo or platelet transfusion-only control group. Although this is the largest study of thrombopoietic growth factor treatment of CIT to date, and the first to include patients with non-myeloid hematologic malignancy, the number of patients with hematologic malignancy was low.

In conclusion, romiplostim is effective for the management of CIT in patients with solid tumors, as demonstrat- 
ed by improved platelet counts and low rates of chemotherapy dose reductions and treatment delays, bleeding, and platelet transfusions. VTE rates approximated rates in similar cancer populations not receiving romiplostim. Weekly dosing resulted in improved outcomes as compared with more intermittent intracycle dosing. Romiplostim was generally ineffective in patients with BM invasion by tumor, prior pelvic irradiation, and prior exposure to temozolomide.

\section{Disclosures}

HA-S has had a consultancy role for Agios, Dova, Rigel, Argenx, and Sobi, and has received research funding from Agios, Dova, and Amgen; ADP has had a consultancy role for Sunovion, has received research funding from Genentech/Hoffman LaRoche, and Shire/Takeda, and sits on the scientific advisory boards of Bayer, and Shire/Takeda; JIW has had a consultancy role for AbbVie; JMC sits on the scientific advisory boards of Bristol-Myers Squibb, and Portola, has had a consultancy role for Bristol-Myers Squibb, has received personal fees from Bristol-Myers Squibb, and sits on the data safety monitoring board of Unum Therapeutics; DJK has received research funding from Protalex, Bristol-Myers Squibb, Rigel, Bioverativ, Agios, Syntimmune, Principia, and Alnylam, and has had a consultancy role for ONO, Pfizer, 3SBios, Eisai, GlaxoSmithKline,
Genzyme, Shire, Amgen, Shionogi, Rigel, Syntimmune, MedImmune, Novartis, Alexion, Bioverativ, Argenx, Zafgen, Fujifilm, Principia, Kyowa Kirin, Takeda, and the Platelet Disorders Support Association.

\section{Contributions}

HA-S wrote the first draft of the manuscript and contributed to study design, data collection, data analysis, creation of tables and figures, critical revision of the manuscript, and final approval of the manuscript for publication; ADP contributed to romiplostim treatment pathway design, data collection, revision of the manuscript, and final approval of the manuscript for publication; $K G$, $J I W$ and JMC contributed to romiplostim treatment pathway design, revision of the manuscript, and final approval of the manuscript for publication; DJK contributed to romiplostim treatment pathway design, critical revision of the manuscript, and final approval of the manuscript for publication.

\section{Acknowledgments}

Hemophilia Foundation-Shire Clinical Fellowship Award, the Harvard Catalyst Medical Research Investigator Training Award, and the American Society of Hematology Scholar Award. We also acknowledge the Harvard Catalyst Biostatistics Team, and in particular Dr. Douglas Hayden, for biostatistical support in this study.

\section{References}

1. Kuter DJ. Managing thrombocytopenia associated with cancer chemotherapy. Oncology (Williston Park). 2015;29(4):282294.

2. Wu Y, Aravind S, Ranganathan G, Martin A, Nalysnyk L. Anemia and thrombocytopenia in patients undergoing chemotherapy for solid tumors: a descriptive study of a large outpatient oncology practice database, 2000-2007. Clin Ther. 2009;31 Pt 2:2416-2432

3. Denduluri N, Patt DA, Wang Y, et al. Dose delays, dose reductions, and relative dose intensity in patients with cancer who received adjuvant or neoadjuvant chemotherapy in community oncology practices. J Natl Compr Canc Netw. 2015:13(11):1383-1393.

4. Elting LS, Rubenstein EB, Martin CG, et al. Incidence, cost, and outcomes of bleeding and chemotherapy dose modification among solid tumor patients with chemotherapy-induced thrombocytopenia. J Clin Oncol. 2001;19(4):1137-1146.

5. Moskowitz CH, Hamlin PA, Gabrilove J, et al. Maintaining the dose intensity of ICE chemotherapy with a thrombopoietic agent, PEG-rHuMGDF, may confer a survival advantage in relapsed and refractory aggressive non-Hodgkin lymphoma. Ann Oncol. 2007;18(11):1842-1850.

6. Aspinall SL, Good CB, Zhao X, et al. Adjuvant chemotherapy for stage III colon cancer: relative dose intensity and survival among veterans. BMC Cancer. 2015;15:62.

7. Havrilesky LJ, Reiner M, Morrow PK, Watson $\mathrm{H}$, Crawford J. A review of relative dose intensity and survival in patients with metastatic solid tumors. Crit Rev Oncol Hematol. 2015;93(3):203-210.

8. Hanna RK, Poniewierski MS, Laskey RA, et al. Predictors of reduced relative dose intensity and its relationship to mortality in women receiving multi-agent chemotherapy for epithelial ovarian cancer. Gynecol Oncol. 2013;129(1):74-80.

9. Kuter DJ, Rummel M, Boccia R, et al. Romiplostim or standard of care in patients with immune thrombocytopenia. N Engl J Med. 2010;363(20):1889-1899.

10. Townsley DM, Scheinberg P, Winkler T, et al. Eltrombopag added to standard immunosuppression for aplastic anemia. $\mathrm{N}$ Engl J Med. 2017;376(16):1540-1550.

11. Afdhal NH, Dusheiko GM, Giannini EG, et al. Eltrombopag increases platelet numbers in thrombocytopenic patients with HCV infection and cirrhosis, allowing for effective antiviral therapy. Gastroenterology. 2014;146(2):442-452 e441.

12. Al-Samkari H, Marshall AL, Goodarzi $\mathrm{K}$, Kuter DJ. Romiplostim for the management of perioperative thrombocytopenia. Br J Haematol. 2018;182(1):106-113.

13. Terrault $\mathrm{N}$, Chen $\mathrm{YC}$, Izumi $\mathrm{N}$, et al. Avatrombopag before procedures reduces need for platelet transfusion in patients with chronic liver disease and thrombocytopenia. Gastroenterology. 2018; 155(3):705-718.

14. Tateishi R, Seike M, Kudo M, et al. A randomized controlled trial of lusutrombopag in Japanese patients with chronic liver disease undergoing radiofrequency ablation. J Gastroenterol. 2018;54(2):171-181.

15. Kumagai Y, Fujita T, Ozaki M, et al. Pharmacodynamics and pharmacokinetics of AMG 531, a thrombopoiesis-stimulating peptibody, in healthy Japanese subjects: a randomized, placebo-controlled study. J Clin Pharmacol. 2007;47(12):1489-1497.

16. Jenkins IM, Williams D, Deng Y, et al. Phase 1 clinical study of eltrombopag, an oral, nonpeptide thrombopoietin receptor agonist. Blood. 2007:109(11):4739-4741.

17. Nomoto M, Pastino G, Rege B, Aluri J, Ferry J, Han D. Pharmacokinetics, pharmacodynamics, pharmacogenomics, safety, and tolerability of avatrombopag in healthy
Japanese and white subjects. Clin Pharmacol Drug Dev. 2018;7(2):188-195.

18. Parameswaran R, Lunning M, Mantha S, et al. Romiplostim for management of chemotherapy-induced thrombocytopenia. Support Care Cancer. 2014;22(5):12171222

19. Miao J, Leblebjian H, Scullion B, Parnes A. A single center experience with romiplostim for the management of chemotherapy-induced thrombocytopenia. Am J Hematol. 2018:93(4):E86-E88.

20. Al-Samkari H, Marshall AL, Goodarzi K, Kuter DJ. The use of romiplostim in treating chemotherapy-induced thrombocytopenia in patients with solid tumors Haematologica. 2018;103(4):e169-e172.

21. Soff GA, Miao Y, Bendheim G, et al. Romiplostim treatment of chemotherapyinduced thrombocytopenia. J Clin Oncol. 2019:37(31):2892-2898.

22. Tepler I, Elias L, Smith JW 2nd, et al. A randomized placebo-controlled trial of recombinant human interleukin-11 in cancer patients with severe thrombocytopenia due to chemotherapy. Blood. 1996; 87(9):3607-3614.

23. Vadhan-Raj S, Verschraegen CF, BuesoRamos C, et al. Recombinant human thrombopoietin attenuates carboplatininduced severe thrombocytopenia and the need for platelet transfusions in patients with gynecologic cancer. Ann Intern Med. 2000;132(5):364-368

24. Basser RL, Underhill C, Davis I, et al. Enhancement of platelet recovery after myelosuppressive chemotherapy by recombinant human megakaryocyte growth and development factor in patients with advanced cancer. J Clin Oncol. 2000;18(15):2852-2861.

25. Neumann TA, Foote M. Megakaryocyte growth and development factor (MGDF): an Mpl ligand and cytokine that regulates thrombopoiesis. Cytokines Cell Mol Ther. 2000;6(1):47-56. 
26. Consensus Committee of Chemotherapy Induced Thrombocytopenia CSoCO. [Consensus on clinical diagnosis, treatment and prevention management of chemotherapy induced thrombocytopenia in China(2018)]. Zhonghua Zhong Liu Za Zhi. 2018:40(9):714-720.

27. Demeter J, Istenes I, Fodor A, et al. Efficacy of romiplostim in the treatment of chemotherapy induced thrombocytopenia (CIT) in a patient with mantle cell lymphoma. Pathol Oncol Res. 2011;17(1):141143
28. Villano JL, Letarte N, Yu JM, Abdur S, Bressler LR. Hematologic adverse events associated with temozolomide. Cancer Chemother Pharmacol. 2012;69(1):107113.

29. Wun T, White RH. Epidemiology of cancerrelated venous thromboembolism. Best Pract Res Clin Haematol. 2009;22(1):9-23.

30. Khorana AA, Dalal M, Lin J, Connolly GC. Incidence and predictors of venous thromboembolism (VTE) among ambulatory high-risk cancer patients undergoing chemotherapy in the United States. Cancer.
2013;119(3):648-655

31. Haas SK, Freund M, Heigener D, et al. Lowmolecular-weight heparin versus placebo for the prevention of venous thromboembolism in metastatic breast cancer or stage III/IV lung cancer. Clin Appl Thromb Hemost. 2012;18(2):159-165

32. Carrier M, Abou-Nassar K, Mallick R, et al. Apixaban to prevent venous thromboem bolism in patients with cancer. N Engl Med. 2019;380(8):711-719. 